\title{
Muscle spasms associated with Sudeck's atrophy after injury
}

\author{
C D MARSDEN, J A OBESO, M M TRAUB, J C ROTHWELL, H KRANZ, F LA CRUZ
}

\begin{abstract}
Four patients developed abnormal involuntary movements of a limb after injury. All subsequently developed sympathetic algodystrophy with Sudeck's atrophy and then abnormal muscle spasms or jerks of the affected limb, lasting years. Sympathetic block in three patients did not relieve the abnormal movements. Two patients obtained partial recovery spontaneously, but the other two required surgery for relief.

The pathophysiology of this condition remains to be determined but the evidence suggests that it is a distinct, disabling clinical syndrome.
\end{abstract}

\section{Introduction}

Trauma to a limb (often minor) is occasionally followed by severe pain and trophic changes characteristic of sympathetic algodystrophy (Sudeck's atrophy). The pathophysiology of the condition is unknown. Even more rarely minor trauma may provoke not only Sudeck's atrophy but also involuntary movements. The clinical picture is so unusual that such patients may be labelled as "hysterical," particularly when compensation is being considered. We, however, have seen four similar cases of muscle spasms associated with Sudeck's atrophy after mild trauma in three different countries. We believe this to be a distinct clinical syndrome, although of unknown pathophysiology.

University Department of Neurology, King's College Hospital Medical School and Institute of Psychiatry, London SE5 8AF

C D MARSDEN, FRCP, FRS, professor of neurology

$M$ M TRAUB, PHD, MRCP, senior registrar

J C ROTHWELL, PHD, Royal Society research fellow

Clinica Universitaria, University of Navarra, Medical School, Pamplona, Spain

J A OBESO, MD, consultant neurologist

F LA CRUZ, MB, research fellow

The Alfred Hospital, Melbourne, Australia

H KRANZ, MD, consultant neurologist

Correspondence to: Professor C D Marsden.

\section{Case 1}

A 50 year old woman was admitted to the Maudsley Hospital, London, in 1981. Two years previously she had fractured her left second metacarpal in a fall. The pain due to bruising settled over a few weeks but she then developed severe burning discomfort and hyperpathia over the thenar eminence and radiating into the index finger, together with trophic changes typical of Sudeck's atrophy. The symptoms failed to respond to various procedures including stellate ganglion block and steroid injections into the carpal tunnel. One year after the accident abnormal movements of the left hand began. Initially they were intermittent but over a few months they became continuous, disappearing only during sleep or when the hand was actively employed, as in writing or using a fork.

Examination showed rhythmical flexion and extension of the index and middle fingers at about $4 \mathrm{~Hz}$, which was interrupted after five to 20 jerks by a sustained spasm in which all the fingers flexed into the palm while the thumb extended, the wrist flexed, and sometimes the elbow flexed (fig 1). The spasm lasted for about a second, after which

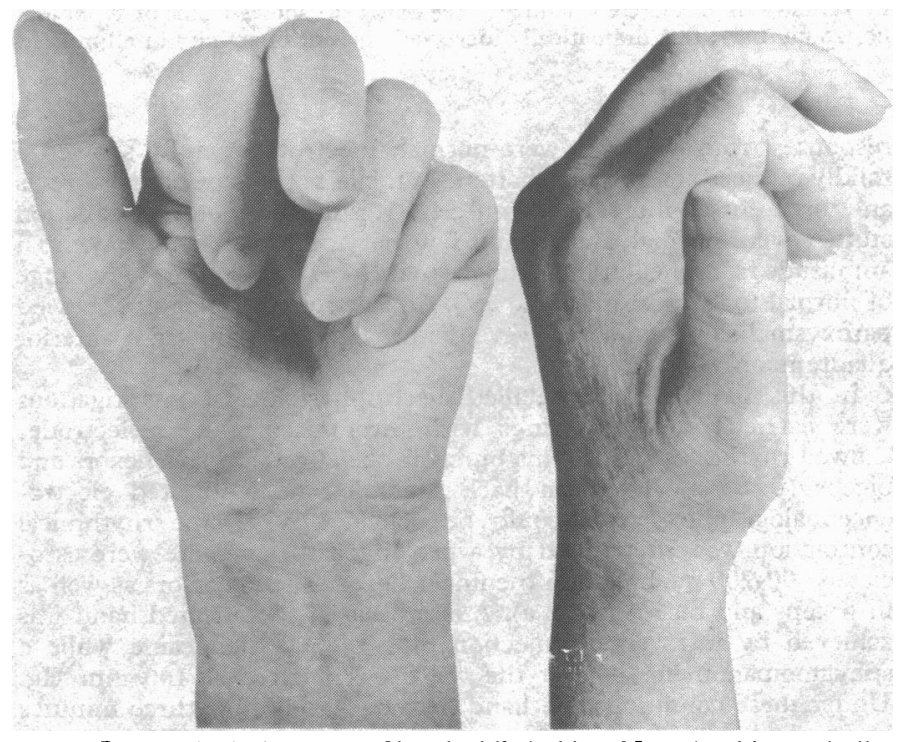

FIG 1-Case 1. Typical posture of hand while jerking. Note the shiny, spindly fingers. 
it was replaced by the rhythmical jerking. When the fingers were passively extended the myoclonic movement started in the thumb, and as soon as the fingers were released a typical spasm occurred. In addition, there was hyperpathia over the whole of the left hand but there was no objective sensory deficit. Physical examination showed no other abnormality.

Results of routine biochemical, haematological, and cerebrospinal fluid investigations were normal. A CT head scan disclosed mild cerebral atrophy and a myelogram showed minimal disc impressions at C5-6 and C6-7. Visual evoked responses and somatosensory evoked although they continued at about the same rate (fig $2 \mathrm{~b}$ ). Vibration of the thenar eminence entrained the tremor at $7 \mathrm{~Hz}$ and increased the amplitude of the bursts about threefold (fig $2 \mathrm{c}$ ). As soon as the vibration was stopped a typical prolonged spasm occurred. The effect of vibration on burst size was in part cutaneous, for it was no longer observed when the skin under the vibrator was anaesthetised, although the rhythmical myoclonus was still slightly entrained.

Treatment was tried with various drugs, including a range of analgesics, anticonvulsants, antidepressants, enkephalins, and dopamine agonists and antagonists, but without success. A stellate ganglion

Intact
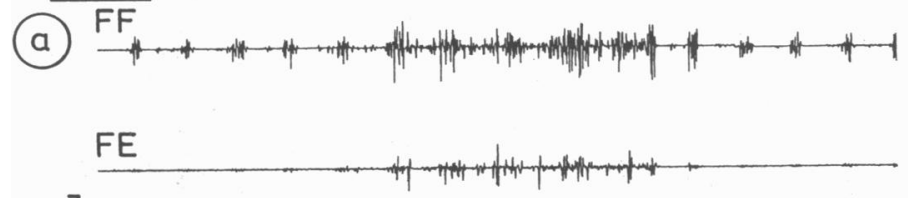

$\left.\begin{array}{c}0.3 \\ \mathrm{mV}\end{array}\right] \mathrm{BIC}$

$$
\text { TRI }
$$
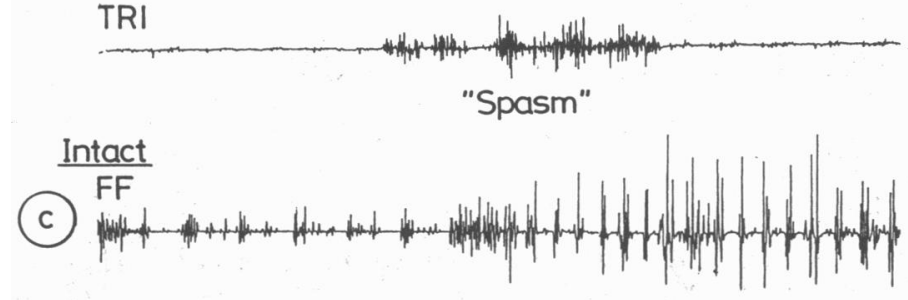

FE
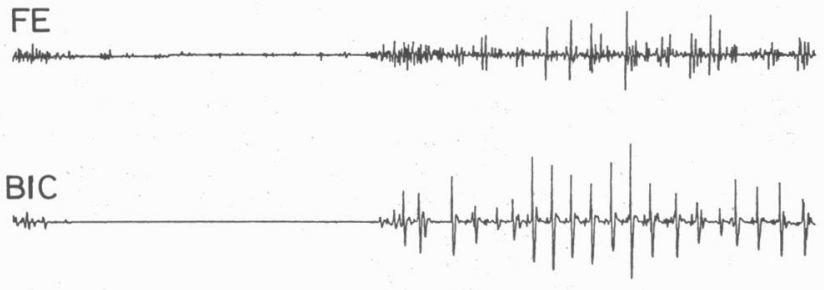

TIC

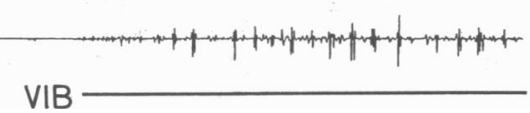

ANAES

FF

(b)

FE

BIC

TRI

FIG 2-Case 1. Part of continuous electromyogram taken from intramuscular wire electrodes inserted into flexor carpi radialis (FF) and extensor carpi radialis longus (FE) of left forearm, and from surface electrodes over biceps (BIC) and triceps brachii (TRI). Upper panel (a) shows continuous rhythmical activity (3-4 Hz) in finger flexors and biceps, with short "spasm" in which activity spread to all muscles recorded. Middle panel (b) shows how activity was reduced by anaesthesia of affected hand. Lower panel (c) shows effect of vibration (VIB; $50 \mathrm{~Hz}$ ) applied to thenar eminence of left hand (for period indicated by horizontal bar); this dramatically increased amount of activity in all muscles and increased frequency of muscle activity from 4 to $7 \mathrm{~Hz}$.

responses from the arms were normal. Electromyography showed a mildly reduced interference pattern in the left abductor pollicis brevis and first dorsal interosseus muscles. Results of motor conduction studies were normal, but the median nerve sensory action potential amplitude from the left index finger to the wrist was at the lower range of normal $(5 \mu \mathrm{V}$; normal 5-50 $\mu \mathrm{V})$. An electroencephalogram showed paroxysmal slow and sharp wave disturbances over the right anterior quadrants.

In this patient more detailed electrophysiological investigations were carried out. Recordings with intramuscular wire electrodes showed rhythmical 30-100 ms bursts in the affected finger flexors and biceps (fig 2 a). Even on back averaging no associated electroencephalographic events could be detected. When the rhythmical contraction was interrupted by a prolonged spasm there were associated $100-200 \mathrm{~ms}$ bursts in the finger flexors and extensors as well as in triceps and biceps (fig 2 a). Anaesthesia of the affected hand was achieved by intravenous injection of $5 \mathrm{ml} 1 \%$ lignocaine while a sphygmomanometer cuff at the wrist was inflated at $100 \mathrm{~mm} \mathrm{Hg}$. Under these conditions the hand became numb after three minutes but normal muscle power was preserved for 10 minutes. The effect of such regional anaesthesia was to depress the amplitude of the jerks, block also had no effect. Over the two years after presentation the patient had some improvement in her pain but the abnormal movements continued unabated. Because of continuous movements and pain a right sided stereotaxic thalamotomy was undertaken. Thermocoagulation of nucleus ventralis intermedius, identified by stereotaxic coordinates and by burst discharges induced by proprioceptive stimuli from the left hand, abolished the movements and reduced the pain.

\section{Case 2}

A 21 year old woman was admitted to King's College Hospital in 1978. She had suffered with psoriasis since the age of 7 , and for four years she had been treated intermittently with anti-inflammatory drugs for a seronegative arthropathy affecting chiefly her wrists, shoulders, and left forefoot. Four months before admission she had developed pain in her left foot after minor trauma, and then abnormal movements of her toes. These became progressively clawed, together with increasing plantar flexion of the foot.

Examination showed pronounced tenderness of the fourth and fifth metatarsals on the left as well as of the long toe flexor tendons. The 
foot was plantar flexed and the toes were curled. There was a rhythmical myoclonus at about $4 \mathrm{~Hz}$ affecting the anterior and posterior tibial muscles, causing alternating flexion and extension of the ankle, which continued during sleep. Tendon jerks were normal but there was hyperpathia to pinprick in the fifth lumbar and first sacral dermatomes on the left.

Results of routine biochemical, haematological, cerebrospinal fluid, and autoimmune studies were normal, as were a myelogram and radiculogram and a CT head scan. Visual evoked responses and somatosensory evoked responses from the legs were normal. An electroencephalogram showed excessive slow wave and sharp wave activity in the right posterior quadrant.

The patient was treated with carbamazepine $800 \mathrm{mg}$ daily and the movements of the toes became irregular and sinuous, but the foot became blue, cold, and shiny. Radiography showed demineralisation consistent with Sudeck's atrophy. A sympathetic block was of no benefit, but over the next three years she made a spontaneous recovery.

\section{Case 3}

A 21 year old woman was referred to the hospital of the University of Navarra, Pamplona, in November 1980 . Eighteen months previously she had damaged her left leg in a fall. Although no fracture had been detected, the leg was put in a below knee plaster for two months. During this time she developed severe pain over gastrocnemius together with paraesthesiae and numbness of the foot. When the plaster was removed the leg remained very cold and painful and the skin was atrophic. By the time she was referred to the neurological department she exhibited obvious changes of Sudeck's atrophy, including radiological evidence of demineralisation of the bones of the left leg. In addition, there was moderate wasting and weakness of the muscles supplied by the left common peroneal nerve. Nerve conduction studies showed a pronounced slowing in this nerve from knee to ankle $(30 \mathrm{~m} / \mathrm{s})$.

In June 1981 a left lumbar sympathectomy was carried out. This did not alleviate the pain. Indeed, swelling of the foot and leg appeared and increased (fig 3). Two months later abnormal movements of the

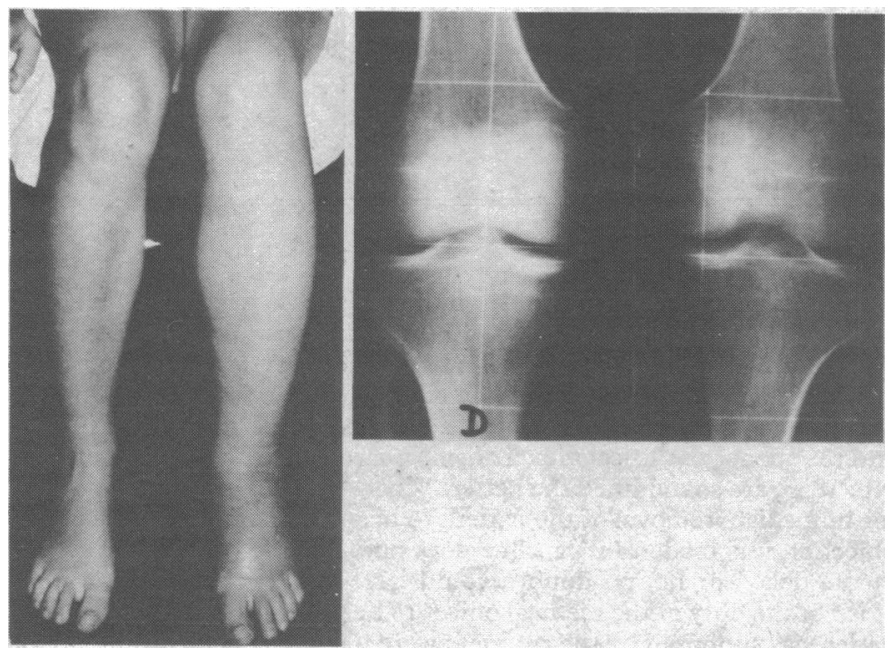

FIG 3-Case 3. Appearances of legs some two and a half years after original injury to left leg. $X$ ray pictures of knees show extensive demineralisation of bones on the left.

foot began, associated with a deep drawing pain in the toes. Examination showed swelling of the left foot and leg with widespread wasting of the muscles above the knee. Continuous flexion and extension jerking movements of the toes and foot were observed at about $4 \mathrm{~Hz}$. These varied in amplitude spontaneously and disappeared during sleep. In addition, there were occasional myoclonic contractions of the left quadriceps.

Routine investigations including electroencephalography and somatosensory evoked potentials were normal. Radiographs of the left leg showed demineralisation of bones, in keeping with Sudeck's atrophy (fig 3).

Over the subsequent year the patient's condition improved. The movements partly responded to carbamazepine $600 \mathrm{mg}$ a day. There was less pain and swelling and the regular jerking movements of the foot appeared for only a few hours each day, although the toes continued to move in a continuous chaotic writhing fashion.

\section{Case 4}

A 39 year old woman was admitted to the Alfred Hospital, Melbourne, in 1982 . Eighteen months previously she had sustained an apparently trivial injury when she had twisted her left ankle. The pain in this joint did not settle despite a period of rest and immobilisation in a plaster cast and the foot became increasingly swollen. Six months after injury she began to experience episodes consisting of brief jerks of plantar flexion and inversion of the left foot, occurring 10 to 12 times each day. Nine months after injury she developed involuntary spasms of her left foot. Initially these lasted five minutes or so, but gradually they lasted longer. Eventually they would persist for up to 30 hours at a time, including during sleep, with about 48 hours of interim freedom. The spasms initially consisted of a movement similar to the earlier jerks, but with time they became confined to the short toe flexors. In association with the spasms she complained of severe pain in the left foot and required pethidine for analgesia; carbamazepine, diazepam, and dantrolene were administered without benefit.

On examination, during the prolonged spasm the left foot and toes were plantar flexed. Active and passive movements of the ankle were normal, confirming that only the intrinsic foot muscles were affected. There were no other neurological signs.

Results of routine investigations including an electroencephalogram and a myelogram were normal. Nerve conduction studies showed slowing in the left posterior tibial nerve from knee to ankle $(33 \mathrm{~m} / \mathrm{s})$ but there was no electromyographic evidence of denervation. Radiographs of the left leg confirmed the diagnosis of Sudeck's atrophy, showing demineralisation of the left tarsal and metatarsal bones.

After the spasms had been stopped by local anaesthetic injected around the posterior tibial nerve behind the medial malleolus a heat coagulation lesion of the nerve was made at open operation. This procedure completely relieved the spasms while causing only patchy numbness of the sole of the foot. Four months later there was a recurrence of spasms and the procedure was repeated with further but transient relief.

\section{Discussion}

All of these four patients developed severe pain, Sudeck's atrophy, and muscle spasms of a limb after trauma. The clinical picture of the involuntary movements was variable. Rhythmical myoclonus was present in cases 1 to 3 , but in cases 1,2 , and 4 there were also sustained muscle spasms. In cases 1 and 3 the movements abated during sleep, whereas in cases 2 and 4 they continued. There was an initial immediate beneficial response to carbamazepine in cases 2 and 3, while in cases 1 and 4, in which interference with afferent input reduced or abolished the spasms, anticonvulsants were ineffective.

In most abnormal movement disorders the abnormality is proved or assumed to lie within the central nervous system. In our patients, however, a peripheral origin for the disturbance was suggested $(a)$ by the association with Sudeck's atrophy, (b) by the history of preceding trauma, and $(c)$ by the electrophysiological evidence of nerve damage in the relevant limb.

The most common form of muscle spasm in which peripheral nerve injury is implicated is that affecting the face. Hemifacial spasm is only rarely caused by pressure on the facial nerve by a gross lesion such as a tumour or aneurysm. Janetta et al, however, maintain that in the great majority of cases an abnormal leash of vessels can be found compressing the proximal part of the facial nerve, ${ }^{1}$ although this claim has been disputed. ${ }^{2}$

Muscle spasms in limbs after local injury were first described by Weir Mitchell among victims of bullet wounds who required amputation in the American civil war. ${ }^{3}$ In several patients the remaining stump developed tremor, choreiform movements, or prolonged spasms, sometimes in association with intolerable pain. It is uncertain whether these abnormal movements originated peripherally, as such patients also suffered severe systemic 
illness after their injuries and may have incurred additional damage to the central nervous system. Certainly such a disorder has not been reported in more recent warfare, in which there has been a higher standard of medical care.

A syndrome of "painful legs and moving toes" was described by Spillane et $a l .{ }^{4}$ In that condition patients develop diffuse pain in the foot or leg in association with involuntary sinuous athetoid movements of the toes but without Sudeck's atrophy. Some patients apparently develop "painful legs and moving toes" after damage to a peripheral nerve or roots, ${ }^{5}$ but in others the condition may occur spontaneously or after minor limb trauma. ${ }^{6}$

Rhythmical myoclonus of peripheral origin has been described infrequently. Foerster observed a patient who after recovery from a radial nerve palsy developed continuous rhythmical contractions of extensor carpi radialis longus. ${ }^{7}$ Said and Bathien reported rhythmical myoclonus of quadriceps related to the infiltration of the femoral nerve by a sarcoma. ${ }^{8}$ One of us (CDM) has also seen a ballet dancer who after a clumsy leap felt a tearing pain in the right hamstrings which was followed by rhythmical myoclonic flexion of the right knee at $2-3 \mathrm{~Hz}$ which persisted for months afterwards. Of particular interest is a patient described by Patrikios who, after a radial nerve injury, developed rhythmical spasms not only by supinator and triceps but also of biceps, ${ }^{9}$ which is supplied by the musculocutaneous nerve. The development of myoclonus in two peripheral nerve territories originating from a single lesion suggests that the abnormal discharges were arising in afferent fibres but were mediated via the spinal cord. There is no proof that the same mechanism operated in our patients, but the hypothesis is supported by Nathan. ${ }^{5} \mathrm{He}$ argued that when a peripheral lesion provokes large coordinated movements of a limb, as observed in our patients, the abnormal firing is probably initiated in afferent fibres and the correct timing and reciprocal innervation is achieved through the action of spinal interneurones.

In the absence of pathological information the mechanism of the abnormal movements in our patients is open to speculation. Hopefully, however, this description will allow others to recognise the syndrome of muscle spasms associated with Sudeck's atrophy after trauma as a relevant disabling entity.

\section{ADDENDUM}

Since submitting this paper we have seen a further patient with a similar syndrome. A 76 year old woman developed typical symptoms of a right carpal tunnel syndrome, for which she had had a surgical decompression four years previously. After that operation she developed increasing burning pain in the right hand and arm, redness with swelling of the right hand, and difficulty lifting the right shoulder. A year before admission, the fingers of the right hand had begun to flex spontaneously into the palm. On examination the right fingers and wrist were held in a typical dystonic posture, with superimposed athetoid movements of the fingers. Radiographs of the right hand confirmed the presence of Sudeck's atrophy. A bone scintiscan showed increased blood flow in the right hand, confirmed by plethysmography. A right sympathetic stellate ganglion block had no effect on the abnormal movements of the hand or the pain.

\section{References}

1 Janetta PJ, Abassy M, Maroon JC, Ramos FM, Abir J. Etiology and definitive microsurgical treatment of hemifacial spasm. F Neurosurg 1977; 47:321-8.

2 Kaye AH, Adams CBT. Hemifacial spasm; a long-term follow-up of patients treated by posterior fossa surgery and facial nerve wrapping. $\mathcal{F}$ Neurol Neurosurg Psychiatry 1981;44:1100-3.

3 Weir Mitchell S. Injuries of nerves and their consequences. New York: Dover Publications, 1977:363-8.

4 Spillane JD, Nathan PW, Kelly RE, Marsden CD. Painful legs and moving toes. Brain 1971;94:541-56.

5 Nathan PW. Painful legs and moving toes: evidence on the site of the lesion. 7 Neurol Neurosurg Psychiatry 1978;41:934-9.

6 Schott GD. "Painful legs and moving toes": the role of trauma. $\mathcal{F}$ Neurol Neurosurg Psychiatry $1981 ; 44: 344-6$.

7 Foerster O. Symptomatologie der Erkranken des rüchenmarkes. In: Bumke O, Foerster O, eds. Handbuch der Neurologie. Vol 5. Berlin: Springer, 1936:196-7.

${ }^{8}$ Said G, Bathien N. Myoclonies rhythmées du quadriceps en relation avec un envalessment sarcomateux du nerf crural. Rev Neurol (Paris) 1977; 133:191-8.

9 Patrikios J. Automatisme moteur rythmique et contiue après lésion d'un nerf périphérique. Rev Neurol (Paris) 1949;81:932-40.

(Accepted 27 October 1983)
ONE HUNDRED YEARS AGO It is difficult to convince the bureaucratic mind that, in dealing with sickness and disease, it is absolutely necessary to make provision for exceptional cases, and to recognise that the responsible medical officer is the proper person to decide questions of life and death. A poor woman living at Ballyroughan, near New Ross, was taken ill on February 19th and 20th; on February 25th, Dr. Carey, the medical officer of the St. Mullins Dispensary District, saw the patient, and finding that she was suffering from typhus fever, certified that she was "in a fit state to be removed to the" Fever Hospital at New Ross. The patient's husband had then to walk eight miles across a mountain to the relieving officer, who wrote an order for a van and nurse to be sent from New Ross, nine miles off, to Ballyroughan; the husband, who had to return to his wife and children, for two children were suffering from fever, sent the order to be posted at Borris, a distance of ten miles. Owing to the necessity to observe these formalities, the van did not arrive at the sick woman's house until forty-eight hours after it was ordered, and the patient died in the Fever Hospital on the following day. An attempt was made to cast blame on Dr. Carey on two grounds: firstly, because he was not present when the woman was removed; and, secondly, because he had not ordered her stimulants; but it is quite clear that Dr. Carey acted up to his duty. He visited the patient immediately after the ticket requiring his presence had been presented to him, and, recognising the nature of the case, he acted properly in ordering her removal to hospital as speedily as possible. The patient was certified to be in a fit state to be removed, and the orders of the Local Government Board were complied with. It appears, from the circular letter of the Board of October 9th, 1883, that the medical officer should not, even in a case of urgency, go so far as to recommend the workhouse master to admit the patient, unless the relieving officer could not be found. In this case,

the relieving officer was found. In country districts, where considerable distances have to be travelled, and much time occupied, in observing formalities, it would be for the public benefit if the medical officers were authorised to act as they saw fit in serious or urgent cases of illness, with reference to conveyance and admission of patients to hospital; and the sooner the Local Government Board's instructions of October 9th, 1883, are so modified the better. When Dr. Carey issued the order for immediate removal of the patient to hospital, his duty ended, as no objection was made to it; and he does not appear to have been aware of the delay, or he, no doubt, would have visited the patient again. It is not the duty of the medical officer to be present at the removal of a patient, as supposed by the coroner; were it so, the doctor would often have to wait many hours and neglect other cases. If Dr. Carey could have given the order on his own authority alone, the woman could, according to the evidence of the relieving officer, have been removed the same day. With regard to the second point, Dr. Carey stated in evidence that he had no power to order stimulants. From a full review of the facts, it would appear that the patient died on the ninth or tenth day of typhus fever; and it should be remembered that, even the best cared patients, with every comfort and necessary at hand, who have not been removed to hospital or elsewhere, very frequently die of typhus about that day of the disease, especially persons from thirty to fifty years of age. No one can say whether the patient would not have died at home on the same day, in the receipt of every care and attention; but the case discloses a state of things which is a reproach to the Local Government Board of Ireland; and we trust that the Board will take steps to remedy the evil brought so forcibly under their notice by the case of this poor woman. (British Medical fournal 1884 ;i: 577.) 